Научная статья

УДК 316.42

DOI: $10.18101 / 1994-0866-2020-4-31-38$

\title{
ПОВСЕДНЕВНАЯ ЖИЗНЬ ЧЕЛОВЕКА В УМНОМ ГОРОДЕ
}

\author{
(C) Бадмаева Маина Харлановна \\ аспирант, \\ Бурятский государственный университет имени Доржи Банзарова \\ Россия, 670000, г. Улан-Удэ, ул. Смолина, 24а \\ badmaevamaina@gmail.com
}

\begin{abstract}
Аннотация. В работе рассмотрены актуальные проблемы повседневности в умном городе, показано, как в современных условиях технологического развития меняется повседневная жизнь человека. В умном городе цифровые технологии влияют на весь комплекс социальных отношений. Новый технологический уклад радикальным образом меняет человеческую повседневность, телесность и способность к творчеству. Внедрение интернета вещей, систем искусственного интеллекта, средств самоулучшения человека и обеспечения ему комфорта заставляет задуматься о границах человеческого и определении его сущности. На примере умного города Сингапур, где наиболее активно внедряются технологические инновации, рассмотрены отрицательные и положительные стороны внедрения концепции умного города. Автор рассматривает особенности внедрения цифровых технологий в обыденную жизнь горожанина. С точки зрения автора статьи, современная социальная философия призвана выработать такие гармоничные мировоззренческие парадигмы существования человека, которые бы основывались на вере в человека как в существо нравственное, творческое и растущее, способное осуществлять самостоятельный выбор.
\end{abstract}

Ключевые слова: умный город; интернет вещей; искусственный интеллект; умный дом; повседневность; цифровизация; Сингапур.

\section{Для цитирования}

Бадмаева М. Х. Повседневная жизнь человека в умном городе // Вестник Бурятского государственного университета. Философия. 2020. Вып. 4. С. 31-38.

Повседневность как одна из жизненных структур человеческого бытия в настоящее время активно изучается различными научными направлениями. Такую бурную исследовательскую деятельность породили резкие изменения в сфере экономики, политики, культуры, образования, которые принципиальным образом изменили когда-то обыденную жизнь современного горожанина. Повседневность сегодня осмысливается как реальность, которая занимает большую часть человеческой жизни, как новая ценность, нечто безусловно положительное и необходимое. Повседневность включает в себя такие простые и «естественные» ценности и идеи, как труд, семья, жизненные приоритеты, пищевые привычки и т. п.

Исследование повседневности на современном этапе развития культуры, когда технологии стали неотъемлемой частью жизни человека, заставляет ученых обратить внимание на проблемы современных городов, которые превратились в 
своеобразную социальную лабораторию и точку концентрации важнейших экономических, финансовых и политических процессов. Бурное развитие городов порождает множество проблем как технологического, так и социальноэкономического характера. Например, в современном обществознании существенно возрос интерес к проблемам городского обустройства, широко обсуждаемым в концепции умного города.

Сегодня не существует общепринятого определения понятия «умный город», но, по нашему мнению, умный город - это совокупность мероприятий, направленных на повышение качества жизни населения за счет цифровизации различных сфер жизнедеятельности города.

В этой связи актуализируется проблема изучения жизненного мира человека в умном городе, находящегося под влиянием перманентных внешних социальных и внутренних антропогенных воздействий, вызванных научно-технической революцией и научно-техническим прогрессом.

Особенную наглядность приобретают эти процессы в таком высокотехнологичном умном городе, как Сингапур. Сингапур попадает в категорию «умные города» по многим параметрам и заслуженно занимает в рейтингах умных городов первые позиции. Индекс IESE Cities in Motion показал, что за 2019 г. Сингапур стал седьмым самым умным городом в мире ${ }^{1}$. В ноябре 2018 г. Всемирный конгресс Smart City Ехро признал Сингапур «Умным городом 2018» [10, с. 6]. Неудивительно, что Сингапур лидирует в соревнованиях умных городов, поскольку курс на развитие в этом направлении был им избран еще в ноябре 2014 г., когда страна запустила программу Smart Nation ${ }^{2}$, направленную на развитие цифровой экономики, цифрового правительства и цифрового общества, которые, по замыслу ее создателей, станут факторами прогрессивного развития здравоохранения, образования, транспорта, финансов и т. д.

В рамках данной программы правительство Сингапура выделило главные проекты: национальная цифровая идентификация (NDI), цифровые транзакции, платформа датчиков Smart Nation, направленных на улучшение деятельности муниципальных служб, совершенствование планирования и безопасности городской жизни. Датчики осуществляют мониторинг качества воздуха, организации движения транспорта и пешеходного движения, процессы использования воды, электрической энергии и т. п. [13, с. 15].

Инновационные технические разработки наводнили дома горожан новейшими смартфонами, компьютерами нового поколения, высокоскоростным интернетом $5 \mathrm{G}$, умной бытовой техникой и т. д.

1 IESE Cities in Motion Index 2019. URL: https://www.ieseinsight.com/ doc.aspx? $\mathrm{id}=2204 \& \mathrm{ar}=\& \mathrm{idi}=2 \& \mathrm{idioma}=2$ (дата обращения: 23.09.2020).

2 IDC's Smart Cities Spending Guide Expands its Coverage to More than 100 Cities, BUSINESS WIRE (Jan. 30, 2019) URL: https://www.businesswire.com/news/ home/20190130005075/en/IDCs-Smart-Cities-SpendingGuide-Expands-Coverage (дата обращени: 23.09.2020). 
Система безопасности в Сингапуре - яркий пример цифровизации повседневной жизни горожан. В стране работает обширная программа полицейского наблюдения. Практически каждое здание в городе, будь это маленький ларек или административное здание, снабжено камерами видеонаблюдения. Относительно недавние исследования компании Comparitech показали, что Сингапур имеет 86000 камер на 5,6 миллиона человек, или 15,25 камеры на 1000 человек ${ }^{1}$. Неудивительно, что Сингапур сегодня известен как один из самых безопасных городов с очень низкими показателями преступности ${ }^{2}$.

В связи с этим происходит бурное развитие интернета вещей, вызванное непрерывно увеличивающимися объемами приобретения гражданами и различными государственными, бизнес-структурами самых разнообразных устройств, способных собирать и передавать информацию. Интернет вещей, порождая распространение цифровых сетей в пределах физического пространства, составляет сегодня своего рода сетевую кровь умного города. Умные города объединяют своими сетями не только поставщиков муниципальных услуг, но и их потребителей, то есть всех участников городской жизни: граждан, государство и бизнес.

Согласно данным из статьи Э. Джеффи, Сингапур примечателен тем, что граждане этой страны не протестуют против тотального контроля, наблюдения или вторжения в их жизнь со стороны государств [10, с. 119]. Правительство Сингапура утверждает, что граждане согласны пожертвовать конфиденциальностью ради безопасности, предсказуемости и прозрачности [12, с. 56]. Это же подтвердилось в недавнем исследовании 30 стран, которое было проведено Boston Consulting Group, The Citizen's Perspective on the Use AI in Government, в котором сингапурцы продемонстрировали положительное отношение к технологиям с искусственными интеллектуальными системами [15, с. 65]. В феврале 2019 г. Сингапур сообщил об удвоении собственных инвестиций в развитие искусственного интеллекта, так как он видит себя в ближайшем будущем неким глобальным центром в сфере тестирования и масштабирования соответствующих технологий [12, с. 89].

Однако столь значительное проникновение в частную жизнь людей многие исследователи критикуют. По их мнению, реальность человека вследствие ее тотальной цифровизации будто обнажается, технологии открывают те сферы жизни, куда доступ прежде был табуирован. Тем самым современный умный город практически уничтожает сугубо личное, интимное пространство человека, делая содержание его жизни открытым для всех. Интересно, что к аналогичному выводу пришел Ж. Бодрийяр, который охарактеризовал современную культуру как порнографическую: «наезд камеры на объект, по сути дела порносъемка, делает

${ }^{1}$ IDC's Smart Cities Spending Guide Expands its Coverage to More than 100 Cities, BUSINESS WIRE (Jan. 30, 2019). URL: https://www.businesswire.com/news/home/ 20190130005075/en/IDCs-Smart-Cities-SpendingGuide-Expands-Coverage (дата обращения: 23.09.2020).

2 Annual Crime Brief 2018, Singapore Police Force, URL: https://www.police.gov. sg/news-andpublications/statistics (дата обращения: 23.09.2020). 
для нас реальным то, что реальностью никогда не было, что всегда имело смысл на некотором расстоянии» [1, с. 107].

Широкое использование технологий в повседневной жизни приводит к значительным изменениям в материальной и духовной жизни человека. Несомненно, что постоянно растущий объем новых знаний, информации и технологий лучше адаптируют человека к новой реальности, привносят в его жизнь комфорт и удобство. Но этим их влияние не исчерпывается. Они воздействуют на трудовые, бытовые, семейные отношения людей, их привычки, духовную жизнь, ценности и приоритеты. Структура социальной реальности трансформируется настолько, что появляется возможность говорить о появлении нового состояния социального, нового горожанина, пребывающего в совершенно новой среде.

Рассмотрим сферу развлечений современного Сингапура. Здесь сингапурцы активно используют платформу Netflix Originals, которая собирает и обрабатывают данные, полученные от подписчиков, о наиболее понравившихся им фильмах и сериалах, находит похожие по содержанию и предлагает их зрителю1. Таким образом, она продуцирует развлекательный контент. Кому же горожане отдают большинство голосов? Как показывают многочисленные исследования, наибольшую популярностью в Сингапуре имеют конкурс «Сингапурский идол», телевизионные ситкомы и драмы, а также фильмы Джека Нео $[14$, с. 76]. Singapore Idol - это телешоу, наполненное значительными рекламными возможностями и однообразными эпизодами, распространяющими и тем самым укрепляющими идеи меритократии, демократии, нации и мультирасовости, рассчитанное на эмоциональную реакцию аудитории, заставляющее ее потратить свои деньги на созданного индустрией идола, превратив многочисленных зрителей в его фанатов. Самый коммерчески успешный ситком Сингапура «Под одной крышей» изображает семейную жизнь и добрососедство с позиции довольно поверхностного понимания сути человеческих взаимоотношений. Продвигаемые в сериале семейные ценности являются глубоко патриархальными, а демонстрируемая многорасовая гармония основана на стереотипных представлениях о расе и скрываемом убеждении о существующей расовой иерархии. Фильмы Нео стимулируют спрос и производство разнообразных потребительских товаров. Как полагает Д. Элтейд, «власть медиа изменяет базовую структуру повседневной жизни: они входят в рутину повседневности и перестраивают ее в соответствии с собственным расписанием» $[5$, с. 49]. Визуальное содержание властвует над человеком, тотально контролирует его вкусы и предпочтения, формирует и предписывает ему те или иные идеалы. Стоит отметить, что аудитория часто сознательно принимает отупляющий поток стандартизированных и миметических шоу, соглашаясь на идущий от них посыл ради получения поверхностного удовольствия в конце долгого рабочего дня и при подготовке к следующему. В своей знаменитой статье «Диснейлэнд со смертной казнью» У. Гибсон пишет, что

1 IESE Cities in Motion Index 2019. URL: https://www.ieseinsight.com/ doc.aspx?id=2204\&ar=\&idi=2\&idioma=2 (дата обращения: 23.09.2020). 
«сингапурское телевидение это одно большое сплошное разъяснение для сингапурцев, где разыгрываются постановки на различные темы, начиная с традиций и заканчивая потреблением различной продукции» $[8$, с. 4].

Телевидение формирует единую идентичность аудитории на государственном и локальном уровне. Будучи повседневной практикой, встроенной в жизненный мир человека, оно продуцирует ежедневную рутину, привычки и подчиняет бытовую реальность трансляции любимых каналов. Через визуальные образы, демонстрируемые предписания телевидение формирует смысловые программы, жизненные правила и приоритеты: семейные ценности, идеальная работа, здоровье и еда, путешествия, знакомства, спорт и т. д.

Следующая сфера виртуального пространства Сингапура - социальные сети, электронная почта, личные блоги, посещение сайтов, онлайн-игры, участие в различных форумах и чатах. Сингапур сегодня входит в число вовлеченных в интернет городов, где уровень пользования им достигает $82 \%{ }^{1}$. Средняя скорость загрузки составляет около 55,13 Мбит/ $\mathrm{c}^{2}$. Мобильными устройствами в стране пользуются $86 \%$ человек [17, с. 6]. В Сингапуре около 4,4 млн человек являются активными пользователями социальных сетей, что составляет $77 \%$ всей численности населения. 1,9 млн горожан пользуются Instagram, большую часть из этого числа составляет в молодежь в возрасте от 25 до 34 лет, 3,5 млн человек используют Facebook $[15$, c. 5]. Такое широкое внедрение социальных сетей позволяет каждому горожанину расширить количество связей и отношений, когда выбор партнера по общению или отказ осуществляется мгновенным и необременительным способом. Как пишет Б. Веллман, в кругу «непосредственного общения» пребывают не только близкие, но и незнакомые участники, внедренные в систему многоканальных сетей $[2$, с. 50$]$. Новая структура взаимоотношений породила так называемые слабые связи [3, с. 78], которые носят поверхностный и функциональный характер и сопровождаются ритуальной вежливостью. «Слабые связи» сплачивают формально знакомых людей, расширяя при этом пространство ежедневной повседневной коммуникации. Таким образом, социальные сети изменили традиционные повседневные коммуникации, которые строились на понятиях «близкое/далекое». Такие поверхностные связи создают иллюзию связанности с этими «дальними», зачастую отдаляя пребывающих рядом «близких».

В недавнем исследовании, проведенном китайскими учеными, люди в период пандемии начали проводить в социальных сетях вместо стандартных четырех часов по восемь часов в день ${ }^{3}$. Если учитывать время сна, то складывается ситуация постоянного нахождения человека в цифровой реальности. Социальные сети предлагают псевдорешения многих жизненных проблем, формируя подчас его

${ }^{1}$ Statistics Singapore. 2018 Household Expenditure Survey, URL: http://www.singstat. gov.sg. (дата обращения: 23.09.2020).

2 Там же.

${ }^{3}$ IDC's Smart Cities Spending Guide Expands its Coverage to More than 100 Cities, BUSINESS WIRE (Jan. 30, 2019) URL: https://www.businesswire.com/news/home/ 20190130005075/en/IDCs-Smart-Cities-SpendingGuide-Expands-Coverage (дата обращения: 23.09.2020). 
личность на базе социального одобрения в виде лайков, комментариев и любого другого вида внимания. Человек, постоянно пребывая в сети, находится в некоем состоянии полусознания, когда им становится легко манипулировать, подталкивать к чему-либо без принуждения.

В настоящее время социальные сети представляют собой текучее и неоднородное пространство, которое отражает плюральность современной повседневной жизни. Анализируя содержание страниц сингапурских пользователей, социологи подчеркивают, что большая часть из них пользуются социальными сетями для общения, покупок и развлечения ${ }^{1}$. Становится очевидным, что социальные сети служат частным, бытовым интересам, увлечениям. В фокусе внимания оказываются рутинные кадры из повседневной жизни: снимки еды, вид из офиса, многочисленные селфи-снимки. Как писал 3. Бауман, современность и в реальности, и в сети трансформировалась в индивидуализированную и приватизированную версию событий, которая состоит из «бесконечного ряда занятий, в центре коих мы сами, наши собственные мысли о себе» [7, с. 45]. Д. Ланир анализируя воздействие интернета на общество, писал, что социальные сети имеют негативные последствия, поскольку творчество и индивидуальность здесь заменены поверхностными суждениями и необдуманным потреблением [4, с. 6].

Таким образом, можно сделать вывод, что технологические новшества в области коммуникаций в значительной степени трансформировали повседневность современного человека, вызвали к жизни качественно новые виды повседневных практик. Стало очевидно, что воздействие цифровизации на повседневную среду человека имеет дуалистическую природу, оказывая как положительное, так и негативное влияние. С одной стороны, цифровые технологии сделали жизнь значительно удобнее, чем прежде, комфортнее и легче. С другой стороны, жизнь человека сегодня (как показывает опыт Сингапура) представляет собой множество различных «жизненных миров», характеризующихся разной степенью вовлеченности, демонстрирующих реализацию готовых дисциплинарных норм, зачастую лишающих человека свободы, делающих его управляемым и манипулируемым. Сингапурская модель, где актуальна внешняя регламентация и ориентация на якобы благие намерения, на наш взгляд, лишает человека возможности осуществления нравственного выбора. Человек представляется в ней как существо по своей природе злое и преступное, не способное на самостоятельное принятие решений, не способное ни к чему хорошему и поэтому нуждающееся в постоянном контроле, ограничении и направлении. Тем самым нравственный закон как проявление сущности человека перестает существовать, и взамен создается система внешнего правового и цифрового регулирования.

Все это свидетельствует о необходимости выработки в современной социальной философии гармоничных мировоззренческих парадигм существования

IDC's Smart Cities Spending Guide Expands its Coverage to More than 100 Cities, BUSINESS WIRE (Jan. 30, 2019) URL: https://www.businesswire.com/news/home/ 20190130005075/en/IDCs-Smart-Cities-SpendingGuide-Expands-Coverage (дата обращения: 23.09.2020). 
человека в новом «умном» обществе, которые позволили бы ему не утратить собственную сущность, сохранить свое положение в мире и повысить самооценку. Они должны быть основаны на вере в человека как в существо развивающееся, самостоятельное, способное ошибаться и исправлять свои ошибки, совершенствуясь и поднимаясь всякий раз на все более высокий уровень собственной эволюции.

\section{Литература}

1. Бодрийяр Ж. В тени молчаливого большинства, или Конец социального / пер. с фр. Н. В. Суслова. Екатеринбург: Изд-во Урал. ун-та, 2000. С. 93.

2. Веллман Б. Постоянство и преобразование Комьюнити // Доклад Законодательной комиссии Канады. Ассоциация Веллмана. 2001. С. 14.

3. Грановеттер М. Сила слабых связей // Экономическая социология. 2009. Т. 10, № 4. C. 31-47.

4. Ланир Дж. Вы не гаджет. Манифест. М.: Corpus, 2011.320 c.

5. Altheide D. Media Power. Beverly Hills CA: Sage, 1985.

6. Barrett A. Sizing Up Singapore // Harward Political Review. 2011. Мау 18 (Электронный ресурс). URL: http://hpronline.org/world/sizing-up-singapore (дата обращения: 19.09.2020).

7. Bauman Z. Living in Utopia // D. Held, H. L. Moore and K. Young (ed.). Cultural politics in a global age. Oxford, Oxford University Press, 2007. P. 323.

8. Gibson W. Disneyland with the Death Penalty [Электронный ресурc]. URL: http://www.wired.com/wired/archive/1.04/gibson_pr.html (дата обращения: 19.09.2020).

9. Hall S. On postmodernism and articulation // Critical Dialogues in Cultural Studies. London: Routledge, 1996. P. 132-137.

10. Jaffe E. What smart cities can learn from Singapore's Smart Nation, MEDIUM (Apr. 15, 2016). URL: https://medium.com/sidewalk-talk/what-smart-cities-can-learn-fromsingapore-s-smart-natione19a7efefa3a (дата обращения: 23.09.2020).

11. Kwang K. Singapore to 'double down' on artificial intelligence efforts, say Vivian Balakrishnan // Channel News Asia. 2019. Feb. 28. URL: https://www.channelnewsasia. com/news/singapore/singapore-double-artificial-intelligence-effortsbalakrishnan-11298028 (дата обращения: 23.09.2020).

12. Lin J. Singapore is 11th most-surveilled city in the world - but it doesn't even come close to China: Report // Business insider Singapore. 2019. Aug. 20.

13. Poon L., Singapore, City of Sensors, CITYLAB (2017, Apr. 21). URL: https://www.citylab.com/life/2017/04/singapore-city-of-sensors/523392/ (дата обращения: 23.09.2020).

14. Tan K. Cinema and Television in Singapore Resistance in One Dimension. Leiden, Boston, 2008. P. 254.

15. Tan M. Trust, transparency must form pillars of Singapore's AI success // The business times (2019, May 10). URL: https://www.businesstimes.com.sg/garage/trust-transparencymust-form-pillarsof-singapore's-ai-success (дата обращения: 24.10.2020).

16. Wee W. Tech in Asia - connecting Asia's start up ecosystem. 2011. URL: https://www.techinasia.com/singapore-technology-society (дата обращения: 23.10.2020).

17. Yang R. "Artificial Intelligence in Singapore: pervasive, powerful and present // The Business Times. 2018, Aug 03. URL: https://www.businesstimes.com.sg/opinion/artificialintelligence-in-singapore-pervasive-powerful-and-present (дата обращения: 01.09. 2020). 
Статья поступила в редакцию 16.11.2020; одобрена после рецензирования 18.11.2020; принята к публикаџии 25.11.2020.

\title{
EVERYDAY HUMAN LIFE IN A SMART CITY
}

\author{
Maina Kh. Badmaeva \\ Research Assistant of Department of Philosophy, \\ Dorzhi Banzarov Buryat State University \\ 24 Smolina St., Ulan-Ude 670000, Russia \\ badmaevamaina@gmail.com
}

Abstract. The article deals with the topical issues of everyday life in a smart city, shows how the lives of the people are changing in the conditions of technological development. In a smart city digital technology affect the entire range of social relations. The new technological order is radically changing human everyday life, physicality and creative activities. Introduction of the internet of things, artificial intelligence systems, means of self-improvement and provision of comfortable living environment make us think about the bounds of the humanity and their definition. Drawing on the example of Singapore, where technological innovations are most actively introduced, we have considered the negative and positive aspects of introducing the concept of a smart city. The article reveals the features of introducing digital technologies into the everyday life of citizens. From our point of view, modern social philosophy should develop harmonious worldview paradigms of human existence based on faith in the human as a moral, creative and growing being, capable of making independent choices.

Keywords: a smart city; internet of things; artificial intelligence; smart home; everyday life; digitalization; Singapore. 